\title{
Effects of Estrogen on Circulating "Free" and Total 1,25-Dihydroxyvitamin D and on the Parathyroid-Vitamin D Axis in Postmenopausal Women
}

\author{
Chandan Cheema, Bill F. Grant, and Robert Marcus \\ Department of Medicine, Stanford University, Palo Alto, California 94305; and the Aging Study Unit, Geriatrics Research, Education, \\ \& Clinical Center, Veterans Administration Medical Center, Palo Alto, California 94304
}

\begin{abstract}
We evaluated the effect of estrogens on "free" and total calcitriol levels and on the calcitriol response to a hypocalcemic challenge in 12 postmenopausal women, age 55-74 yr. Endogenous calcitriol production was induced by intravenous $\mathrm{Na}$ EDTA before and after conjugated estrogens, $1.25 \mathrm{mg} / \mathrm{d}$ for 30 d. Free calcitriol was determined by centrifugal ultrafiltration and by the molar ratio of calcitriol to vitamin D-binding protein (DBP). Estrogen increased fasting total calcitriol from 38.5 \pm 3.8 to $62.3 \pm 7.0 \mathrm{pg} / \mathrm{ml}(P<0.05)$. This was accompanied by a rise in free calcitriol from $104.5 \pm 11.4$ to $158.7 \pm 16.4$ $\mathrm{fg} / \mathrm{ml}(P<0.05)$. Vitamin D-binding protein increased from $348 \pm 16$ to $428 \pm 12 \mu \mathrm{g} / \mathrm{ml}(P<0.001)$, and the ratio of calcitriol/DBP increased from $1.50 \pm 0.14$ to $1.94 \pm 0.18(P$ $<\mathbf{0 . 0 0 5}$ ), confirming the rise in free calcitriol. Increases in free calcitriol and in calcitriol/DBP ratios were significantly correlated, $r=0.72$. Hypocalcemia led to a rapid increase in circulating immunoreactive parathyroid hormone, and to a rise in calcitriol at $24 \mathrm{~h}$. The hypocalcemia-induced rise in total and free calcitriol was similar before and after estrogen, whether expressed as increments or as percent changes. We conclude that estrogen increases circulating levels of biologically active free calcitriol in postmenopausal women, but that a 30-d period of estrogen administration does not apparently improve the renal $1 \alpha$-hydroxylase response to a PTH challenge.
\end{abstract}

\section{Introduction}

Elevated plasma levels of the active vitamin $\mathrm{D}$ metabolite, $1,25(\mathrm{OH})_{2}$ vitamin $\mathrm{D}$ (calcitriol), have been commonly observed during physiologic states of increased circulating estrogen (1-5) and during administration of either oral contraceptive medications (4) or postmenopausal estrogens (1). However, since estrogen also increases the production of vitamin D binding protein $(6,7)$, an increase in total calcitriol is not necessarily accompanied by a rise in the biologically effective free level. Gallagher et al. (1) showed that the efficiency of intestinal calcium absorption in menopausal women improved in parallel with an estrogen-induced rise in serum calcitriol, suggesting that biologically active calcitriol had indeed increased. However, Crilly et al. (8) reported in an abstract that estrogen treatment of osteoporotic women did not affect either free calcitriol or calcium absorption. We have assessed the effects of estrogen on circulating total and free calcitriol levels

Address reprint requests to Dr. Robert Marcus, GRECC 182-B, Veterans Administration Medical Center, Palo Alto, CA 94304.

Received for publication 22 June 1988 and in revised form $19 \mathrm{Au}$ gust 1988.

The Journal of Clinical Investigation, Inc.

Volume 83, February 1989, 537-542 and on the parathyroid-vitamin $\mathrm{D}$ axis in postmenopausal women. The results constitute the basis for this report.

\section{Methods}

Materials. Crystalline $1,25(\mathrm{OH})_{2}$ vitamin $\mathrm{D}_{3}$ (calcitriol) was the generous gift of Dr. M. Uskokovic (Hoffmann-LaRoche, Nutley NJ). $\left[{ }^{3} \mathrm{H}\right]$ Calcitriol $(176 \mathrm{Ci} / \mathrm{mmol})$, and $\left[{ }^{14} \mathrm{C}\right]$ glucose were purchased from Amersham Corp. (Arlington Heights, IL). Thymus vitamin D-binding protein was purchased from Incstar Corp. (Stillwater, MN). Silica and C-18 SepPak cartridges were purchased from Waters Associates (South San Francisco, CA). Other chemicals and reagents were analytical grade.

Subjects. Healthy postmenopausal women were recruited from a registry maintained by the Aging Study Unit, Veterans Administration Medical Center Palo Alto, of normal elderly men and women in the Palo Alto community. Subjects were invited to participate in this study if they had no chronic or acute illness, were not taking estrogen replacement, thiazide diuretics, glucocorticosteroids, lithium carbonate, anticonvulsant medication, or any other drug known to affect mineral metabolism, and if they had no contraindication to receiving estrogen therapy. Subjects underwent an initial screening procedure which included health history questionnaire, physical examination, electrocardiogram, nutritional assessment, and multiphasic laboratory panel.

12 women, age 55-75 yr, passed the screening criteria and were enrolled into the protocol. One woman had undergone hysterectomy without oophorectomy. One woman received one-grain equivalent of thyroid hormone replacement on a chronic basis. Two women continued their habitual daily supplement of calcium, 500 and $1,000 \mathrm{mg}$, throughout the study. One woman had taken estrogen $(0.3 \mathrm{mg}$ conjugated estrogen/d) for $30 \mathrm{~d},>2$ mo before the study. The protocol was approved by the Human Subjects Committee of Stanford University, and each subject gave written consent.

Protocol. Each subject was studied on two occasions, before and after 1 mo of treatment with conjugated equine estrogens (Premarin, Ayerst), $1.25 \mathrm{mg} / \mathrm{d}$. The overall strategy for each study was to stimulate endogenous production of calcitriol by hypocalcemic induction of PTH secretion. Subjects were admitted to the Aging Study Unit, a clinical investigation ward. After a regular dinner they consumed only water until completion of the infusion the next noon. An initial measurement of the serum calcium concentration was obtained on admission to determine that a hypocalcemic challenge would not present a hazard to the subject. Initial values $>9.0 \mathrm{mg} / \mathrm{dl}$ were deemed acceptable.

At $0900 \mathrm{~h}, 50 \mathrm{mg} \mathrm{NaEDTA} / \mathrm{kg}$ body wt was administered as a sustained infusion until the serum calcium level reached $7.00 \mathrm{mg} / \mathrm{dl}$, or until $6 \mathrm{~h}$ of infusion. The drug was contained in $1,000 \mathrm{ml} 0.9 \%$ saline, and the rate of infusion was controlled by an electronic pump (IVAC intravenous administration unit). Serum calcium was measured every $30 \mathrm{~min}$ throughout the infusion, $2 \mathrm{~h}$ after the infusion was terminated, and at $0900 \mathrm{~h}$ the next morning. Aliquots of serum were stored frozen at $-20^{\circ} \mathrm{C}$ for determination of immunoreactive PTH and calcitriol. 25 hydroxyvitamin $\mathrm{D}(25 \mathrm{OHD})^{1}$ was measured on baseline specimens at each occasion.

1. Abbreviations used in this paper: DBP, vitamin D-binding protein; TmP/GFR, maximal tubular phosphate reabsorption; 25OHD, 25 hydroxyvitamin D. 
After completion of the initial infusion study, subjects were discharged with a 30-d supply of conjugated equine estrogens, $1.25 \mathrm{mg} / \mathrm{d}$. They were readmitted on day 29 , and the EDTA infusion study was repeated on day 30. During the second study, EDTA was infused until hypocalcemia similar to that of the first test had been achieved.

Analytical methods. Mid-molecule PTH was measured by RIA using goat antiserum NG-5 generously supplied by Dr. Lawrence Mallette, as we have described and validated previously (9). 25OHD was measured in serum by a competitive binding method modified from that of Haddad and Chyu after extraction of serum with methanol and purification on C-18 SepPak cartridges (10).

Calcitriol was measured by the sequential SepPak cartridge procedure of Reinhardt and Hollis (11) using calf thymus binding protein as the binder. As recommended by the supplier of the binding protein, the second separation step was slightly modified. Eluates from the first separation step were washed onto the second cartridge with 98:2 instead of $96: 4$ hexane/isopropanol, and elution was carried out with $70: 30$, rather than $85: 15$, hexane/isopropanol. The limit of detection in this assay is $2 \mathrm{pg} / \mathrm{ml}$ with assay linearity to $64 \mathrm{pg} / \mathrm{ml}$. Intra- and interassay coefficients of variation are 5.4 and $11.5 \%$, respectively. All sera for vitamin D metabolites for a given subject were stored frozen until she had completed both infusion protocols, and were processed in a single-assay run.

Free calcitriol was estimated by a modification of the centrifugal ultrafiltration method of Hammond et al. (12) adapted for vitamin D by Bikle et al. (2). $0.1 \mu \mathrm{Ci}\left[{ }^{3} \mathrm{H}\right]$ calcitriol and 7,500 dpm $\left[{ }^{14} \mathrm{C}\right]$ glucose were placed into a $70 \times 100 \mathrm{~mm}$ test tube, and dried under nitrogen. $0.45 \mathrm{ml}$ serum which had been diluted 1:10 in phosphate-buffered saline was added; aliquots were removed, and each was placed in the inner tube of an ultrafiltration vial (12) and centrifuged at $2,000 \mathrm{~g}$ for $90 \mathrm{~min}$ at $37^{\circ} \mathrm{C}$. After centrifugation, $30 \mu \mathrm{l}$ of the contents of the inner tube (representing serum) and the contents of the outer vial (ultrafiltrate) were analyzed for ${ }^{3} \mathrm{H}$ and ${ }^{14} \mathrm{C}$ by liquid scintillation spectroscopy (model LS3801; Beckman Instruments, Fullerton, CA). The percentage of free calcitriol was calculated from the following equation:

$\%$ free $={ }^{3} \mathrm{H}_{\mathrm{u}} /{ }^{14} \mathrm{C}_{\mathrm{u}} \div{ }^{3} \mathrm{H}_{\mathrm{s}} /{ }^{14} \mathrm{C}_{\mathrm{s}} \times 100$,

where $\mathbf{u}=$ ultrafiltrate and $\mathbf{s}=$ serum. The concentration of free calcitriol was calculated by multiplying the measured total calcitriol by the percent free.

Serum calcium was determined by automatic titration against EGTA (Calcette, model 4008; Precision Systems, Inc., Natick, MA). Vitamin $\mathrm{D}$ binding protein was measured by Dr. Roger Bouillon by methods reported previously (13).

Data management. The database was maintained on a personal computer and analyzed with the Crunch statistical software package (Crunch Software, Oakland, CA). Analyses included paired $t$ tests and repeated measures analysis of variance. Probability tests were two tailed. Data are reported as means \pm SEM.

\section{Results}

Characteristics of the study group are shown in Table I. The age range was $55-74 \mathrm{yr}$, mean $=64 \pm 1.9 \mathrm{yr}$. Time since menopause averaged $15.6 \pm 2.7 \mathrm{yr}$. The subjects were vitamin $\mathrm{D}$ replete, with serum $25 \mathrm{OHD}$ levels averaging $34.9 \pm 3.3 \mathrm{ng} / \mathrm{ml}$. Only one woman had a $25 \mathrm{OHD}$ concentration $<20 \mathrm{ng} / \mathrm{ml}$. 2-h endogenous creatinine clearance averaged $93.5 \pm 5.6 \mathrm{ml} /$ $\mathrm{min}$, and was $>60 \mathrm{ml} / \mathrm{min}$ in each case. Fasting serum creatinine concentration for the group was $0.84 \pm 0.03 \mathrm{mg} / \mathrm{dl}$.

Effect of estrogen on baseline values. After estrogen, fasting serum calcium and inorganic phosphorus levels decreased significantly from $9.3 \pm 0.1$ to $9.0 \pm 0.15 \mathrm{mg} / \mathrm{dl}$ and from $3.68 \pm 0.14$ to $3.33 \pm 0.11 \mathrm{mg} / \mathrm{dl}$, respectively $(P<0.05)$ (Table II). Estrogen treatment did not alter fasting iPTH. Total fasting
Table I. Characteristics of the Study Group

\begin{tabular}{|c|c|c|c|c|c|}
\hline Subject & Age & Menopause & $\begin{array}{l}\text { Serum } \\
\text { calcium }\end{array}$ & PTH & $25 \mathrm{OHD}$ \\
\hline & & $y r$ & $m g / d l$ & $p g / m l$ & $n g / m l$ \\
\hline 1 & 61 & 7 & 9.6 & 47.7 & 32.2 \\
\hline 2 & 65 & 10 & 9.0 & 30.0 & 26.5 \\
\hline 3 & 56 & 10 & 9.5 & 34.5 & 54.6 \\
\hline 4 & 64 & 17 & 9.8 & 11.5 & 30.4 \\
\hline 5 & 65 & 25 & 9.1 & 51.8 & 43.5 \\
\hline 6 & 62 & 7 & 8.7 & 55.7 & 27.3 \\
\hline 7 & 55 & 8 & 9.2 & 18.4 & 16.9 \\
\hline 8 & 55 & 5 & 8.9 & 33.8 & 55.6 \\
\hline 9 & 71 & 23 & 9.0 & 25.7 & 34.2 \\
\hline 10 & 74 & 34 & 9.4 & 22.3 & 28.4 \\
\hline 11 & 72 & 24 & 8.8 & 19.2 & 35.9 \\
\hline 12 & 68 & 17 & 10.2 & 34.0 & 33.8 \\
\hline Mean \pm SEM & $64 \pm 1.9$ & $15.6 \pm 2.7$ & $9.3 \pm 0.1$ & $31.9 \pm 4.0$ & $34.9 \pm 3.3$ \\
\hline
\end{tabular}

calcitriol increased on estrogen from $38.5 \pm 3.8$ to $62.3 \pm 7.0$ $\mathrm{pg} / \mathrm{ml}(P<0.05)$ (Table III, Fig. 1$)$.

At baseline, the free calcitriol concentration was $104.5 \pm 11$ $\mathrm{fg} / \mathrm{ml}$, representing $0.279 \pm 0.01 \%$ of total (Table IV). This calcitriol level is significantly lower $(P<0.05)$ than corresponding values obtained for a group of 10 healthy women, age $25-40 \mathrm{yr}$, in whom percent free calcitriol was $0.220 \pm 0.01 \%$, and the free calcitriol concentration was $145 \pm 12 \mathrm{fg} / \mathrm{ml}$. On estrogen, free calcitriol increased significantly to $158.7 \pm 16.4$ $\mathrm{fg} / \mathrm{ml}(P<0.05)$ (Table IV, Fig. 1$)$, a value that was indistinguishable from that of the young controls.

To validate the rise in basal free calcitriol levels on estrogen, vitamin D-binding protein (DBP) was measured on fasting serum before and after estrogen treatment (Table V). Initial DBP was $348 \pm 16 \mu \mathrm{g} / \mathrm{ml}$, increasing significantly to $428 \pm 12 \mu \mathrm{g} / \mathrm{ml}$ on estrogen $(P<0.001)$. The index of free calcitriol, defined as the molar ratio of total calcitriol to DBP, increased significantly on estrogen, from $1.50 \pm 0.14$ to $1.94 \pm 0.18(P<0.005)$. The rise in fasting free calcitriol by centrifugal ultrafiltration correlated significantly with the rise in the calcitriol/DBP ratio, $r=0.72, P<0.05$.

Effect of estrogen on the response to EDTA-hypocalcemia. EDTA infusion lead to a rapid and progressive fall in the serum calcium concentration, with a concomitant rise in iPTH (Fig. 2). The hypocalcemic nadirs with EDTA were simi-

Table II. Biochemical Serum Indices before and after Estrogen

\begin{tabular}{lcc}
\hline & Before estrogen & After estrogen \\
\hline Calcium, basal $(m g / d l)$ & $9.3 \pm 0.13$ & $9.0 \pm 0.15^{*}$ \\
Inorganic phosphorus, basal & & \\
$\quad(m g / d l)$ & $3.68 \pm 0.14$ & $3.33 \pm 0.11^{*}$ \\
EDTA calcium nadir & $7.3 \pm 0.10$ & $7.2 \pm 0.08$ \\
iPTH, basal $(p g / m l)$ & $31.9 \pm 4.05$ & $34.6 \pm 6.4$ \\
EDTA iPTH peak & $79.1 \pm 9.2$ & $71.7 \pm 9.0^{*}$
\end{tabular}

$* P<0.05$ vs. before estrogen. 
Table III. Changes in Total 1,25(OH) ${ }_{2} \mathrm{D}$ after Hypocalcemic Challenge

\begin{tabular}{|c|c|c|c|c|c|c|c|c|}
\hline \multirow[b]{2}{*}{ Subject } & \multicolumn{4}{|c|}{ Before estrogen } & \multicolumn{4}{|c|}{ After estrogen } \\
\hline & Basal & Peak & Increase & $\%$ Rise & Basal & Peak & Increase & $\%$ Rise \\
\hline 1 & $30.9^{*}$ & 38.9 & 8.0 & 25.9 & 36.7 & 52.7 & 16.0 & 43.6 \\
\hline 2 & 29.9 & 39.2 & 9.3 & 31.1 & 45.8 & 60.9 & 15.1 & 33.0 \\
\hline 3 & 34.7 & 40.6 & 5.9 & 17.0 & 35.6 & 56.6 & 21.0 & 59.0 \\
\hline 4 & 25.3 & 37.2 & 11.9 & 47.0 & 36.3 & 53.5 & 17.2 & 47.4 \\
\hline 5 & 30.3 & 51.3 & 21.0 & 69.3 & 39.7 & 58.8 & 19.1 & 48.1 \\
\hline 6 & 68.6 & 80.6 & 12.0 & 17.5 & 86.7 & 115.0 & 28.3 & 32.6 \\
\hline 7 & 57.5 & 56.9 & -0.6 & -1.1 & 80.6 & 101.4 & 20.8 & 25.8 \\
\hline 8 & 33.9 & 67.9 & 34.0 & 100.3 & 79.8 & 109.3 & 29.5 & 37.0 \\
\hline 9 & 35.1 & 54.1 & 19.0 & 54.1 & 84.1 & 90.5 & 6.4 & 7.6 \\
\hline 10 & 46.0 & 36.0 & 10.0 & -21.7 & 85.6 & 58.1 & -27.5 & -32.1 \\
\hline 11 & 26.3 & 51.3 & 25.0 & 95.1 & 43.1 & 61.7 & 18.6 & 43.2 \\
\hline 12 & 44.0 & 64.4 & 20.4 & 46.4 & 93.5 & 83.6 & -9.9 & -10.6 \\
\hline Mean \pm SEM & $38.5 \pm 3.8$ & $51.5 \pm 4.1$ & $13.0 \pm 3.4$ & $40.1 \pm 10.5$ & $62.3 \pm 7.0^{\ddagger}$ & $75.2 \pm 6.8^{\ddagger}$ & $13.0 \pm 4.7$ & $27.9 \pm 7.7$ \\
\hline
\end{tabular}

${ }^{*} 1,25(\mathrm{OH})_{2} \mathrm{D}=$ picograms/milliliter. ${ }^{\ddagger} P<0.05$ vs. before estrogen.

lar before and after estrogen, $7.3 \pm 0.1$ and $7.2 \pm 0.08 \mathrm{mg} / \mathrm{dl}$, respectively. Although peak values for iPTH before and after estrogen did not differ (Fig. 2, Table II), the rise in iPTH with

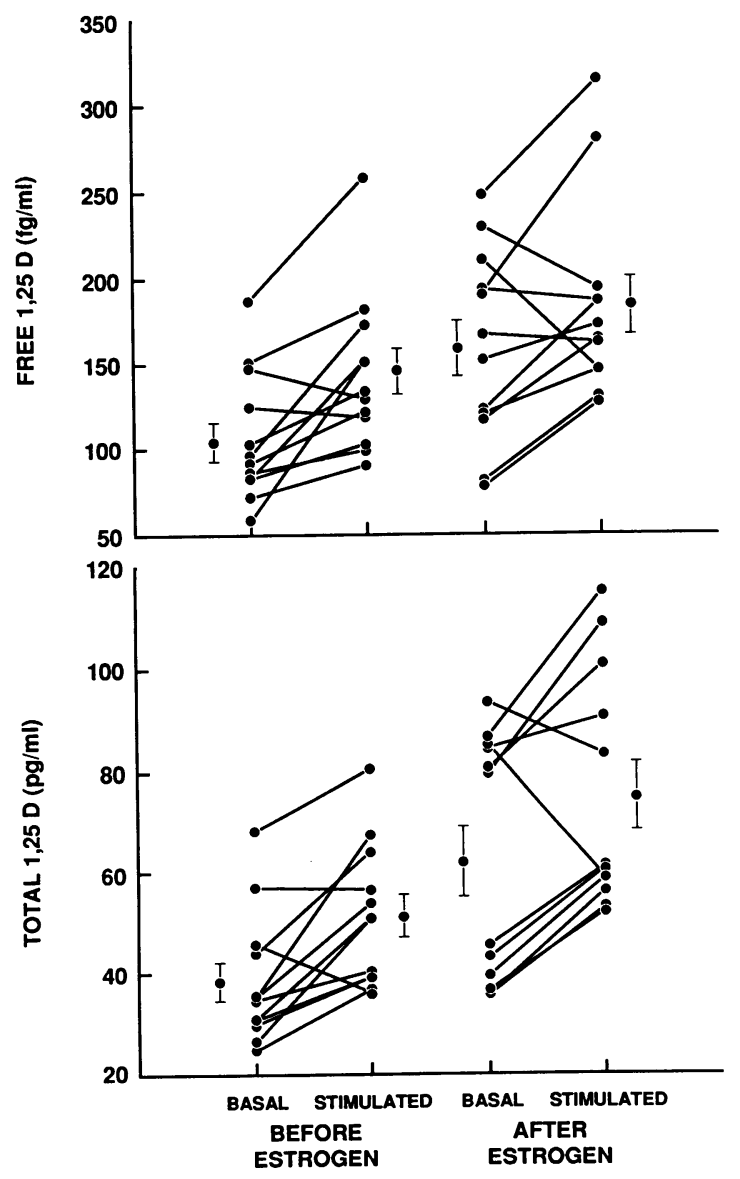

Figure 1. Effect of estrogen on fasting and EDTA-stimulated calcitriol in 12 postmenopausal women. (Top) Free calcitriol values; (bottom) total calcitriol values. Group means \pm SEM are given next to the individual values. hypocalcemia was significantly lower after estrogen than during the first study $(P=0.05)$ (Fig. 2, Table II). Serum calcitriol levels began to rise by $4 \mathrm{~h}$ of the EDTA infusion, and were highest at $24 \mathrm{~h}$ (Fig. 2).

Before estrogen therapy, the hypocalcemic challenge led to significant rises in total calcitriol concentration in 10 of 12 women (Table III) (Fig. 1). The mean baseline value, 38.5 \pm 3.8 $\mathrm{pg} / \mathrm{ml}$, rose to a peak of $51.5 \pm 4.1 \mathrm{pg} / \mathrm{ml}$, representing a $40 \%$ increase of $13.0 \pm 3.4 \mathrm{pg} / \mathrm{ml}$. After estrogen, hypocalcemia increased calcitriol in 10 women, with peak levels of $75.2 \pm 6.8$ $\mathrm{pg} / \mathrm{ml}$ that were significantly higher than those achieved before estrogen. However, the increase from basal, expressed either as absolute rise or fold increase, did not differ significantly from preestrogen values (Fig. 1).

The percent free calcitriol did not change during or after the EDTA infusion. Before estrogen hypocalcemia increased the concentration of free calcitriol in 10 women (Table IV, Fig. 1 ), with a mean increase of $46.4 \pm 13.8 \%$. However, hypocalcemic challenge on estrogen increased free calcitriol in only eight subjects, with four women now showing decreases of 2.7 to $31 \%$. The average increase in free calcitriol on estrogen did not differ significantly from that seen before estrogen treatment, whether expressed as an absolute or fold increase (Table IV, Fig. 1).

Estrogen therapy was well tolerated. Two women complained of transient breast discomfort and ankle swelling. EDTA was tolerated well by all subjects. Three women experienced a mild burning sensation along the arm, but this disappeared several minutes after slowing the infusion rate. No signs or symptoms of hypocalcemia were observed.

\section{Discussion}

We have shown that a brief period of estrogen treatment increased the static blood levels of calcitriol in a group of elderly women. In addition, our results demonstrate that estrogen increased the unbound, free calcitriol fraction in these subjects. To evaluate the change in free sterol we used two independent methods. Using the centrifugal ultrafiltration technique of 
Table IV. Changes in Free $1,25(\mathrm{OH})_{2} \mathrm{D}$ after Hypocalcemic Challenge

\begin{tabular}{|c|c|c|c|c|c|c|c|c|}
\hline \multirow[b]{2}{*}{ Subject } & \multicolumn{4}{|c|}{ Before estrogen } & \multicolumn{4}{|c|}{ After estrogen } \\
\hline & Basal & Peak & Increase & \% Rise & Basal & Peak & Increase & $\%$ Rise \\
\hline 1 & $71.1^{*}$ & 91.4 & 20.3 & 28.6 & 79.3 & 129.1 & 49.8 & 62.8 \\
\hline 2 & 74.2 & 104.3 & 30.1 & 40.6 & 118.0 & 147.4 & 29.4 & 24.9 \\
\hline 3 & 84.0 & 122.8 & 38.8 & 46.2 & 77.6 & 127.4 & 49.8 & 64.2 \\
\hline 4 & 151.3 & 181.9 & 30.6 & 20.2 & 152.8 & 172.8 & 20.0 & 13.1 \\
\hline 5 & 95.8 & 173.4 & 77.6 & 81.0 & 117.5 & 162.9 & 45.4 & 38.6 \\
\hline 6 & 186.6 & 258.9 & 72.3 & 38.8 & 247.1 & 315.1 & 68.0 & 27.5 \\
\hline 7 & 147.2 & 130.3 & -16.9 & -11.5 & 191.0 & 280.9 & 89.9 & 47.1 \\
\hline 8 & 74.6 & 152.1 & 77.5 & 103.9 & 193.1 & 186.9 & -6.2 & -3.2 \\
\hline 9 & 82.5 & 100.6 & 18.1 & 21.9 & 166.5 & 162.0 & -4.5 & -2.0 \\
\hline 10 & 102.6 & 134.3 & 31.7 & 30.9 & 210.6 & 145.3 & -65.3 & -31.0 \\
\hline 11 & 58.6 & 152.4 & 93.8 & 160.1 & 122.0 & 185.7 & 63.7 & 52.2 \\
\hline 12 & 125.2 & 120.4 & -4.8 & -3.8 & 229.1 & 193.1 & -36.0 & -15.7 \\
\hline Mean \pm SEM & $104.5 \pm 11.4$ & $143.6 \pm 13.2$ & $39.1 \pm 10.0$ & $46.4 \pm 13.8$ & $158.7 \pm 16.4^{\ddagger}$ & $184.1 \pm 16.7^{\ddagger}$ & $25.3 \pm 13.2$ & $23.1 \pm 9.1$ \\
\hline
\end{tabular}

* Free $1,25(\mathrm{OH})_{2} \mathrm{D}=$ femtograms/milliliter. $\quad{ }^{\ddagger} P<0.05$ vs. before estrogen.

Hammond et al. (12), we found free calcitriol levels in our postmenopausal subjects to be significantly lower than those of younger women. After estrogen, these levels increased to the normal young range. The concentrations of free calcitriol that we report are reasonably close to, but slightly lower than those described by Bikle et al. (2), a difference that may reflect our use of a 1:10 dilution of serum in the assay in order to enhance the precision of the method.

To confirm the ultrafiltration results, we examined the effect of estrogen on DBP and on the free calcitriol index of Bouillon et al. (4). DBP concentrations before treatment were similar to those reported for normal adult women. On estrogen, DBP rose to levels almost as high as those observed in women taking combination estrogen/progestin contraceptives

Table V. Effect of Estrogen on Vitamin D-binding Protein and on the Molar Ratio of $1,25(\mathrm{OH})_{2} \mathrm{D} / \mathrm{DBP}$

\begin{tabular}{|c|c|c|c|c|}
\hline \multirow[b]{2}{*}{ Subject } & \multicolumn{2}{|c|}{ Vitamin $\mathrm{D}$ binding protein } & \multicolumn{2}{|c|}{$1,25(\mathrm{OH})_{2} \mathrm{D} / \mathrm{DBP}$} \\
\hline & Before estrogen & After estrogen & Before estrogen & After estrogen \\
\hline \multicolumn{5}{|c|}{$\mu g / m l$} \\
\hline 1 & 363 & 425 & 1.14 & 1.26 \\
\hline 2 & 397 & 397 & 1.01 & 1.55 \\
\hline 3 & 337 & 398 & 1.38 & 1.21 \\
\hline 4 & 299 & 344 & 1.14 & 1.42 \\
\hline 5 & 344 & 404 & 1.19 & 1.32 \\
\hline 6 & 483 & 529 & 1.28 & 2.18 \\
\hline 7 & 390 & 425 & 2.36 & 2.74 \\
\hline 8 & 318 & 447 & 1.11 & 1.30 \\
\hline 9 & 350 & 425 & 2.21 & 2.55 \\
\hline 10 & 331 & 469 & 1.43 & 2.41 \\
\hline 11 & 318 & 439 & 1.43 & 2.44 \\
\hline 12 & 256 & 432 & 2.33 & 2.91 \\
\hline Mean \pm SEM & $348 \pm 16$ & $428 \pm 12^{*}$ & $1.50 \pm 0.14$ & $1.94 \pm 0.18^{\ddagger}$ \\
\hline
\end{tabular}

${ }^{*} P<.001, P<.005$ vs. preestrogen.
(4). The index of free calcitriol, or calcitriol/DBP ratio, was initially lower than that reported for adult women, but increased on estrogen to levels observed in young women taking
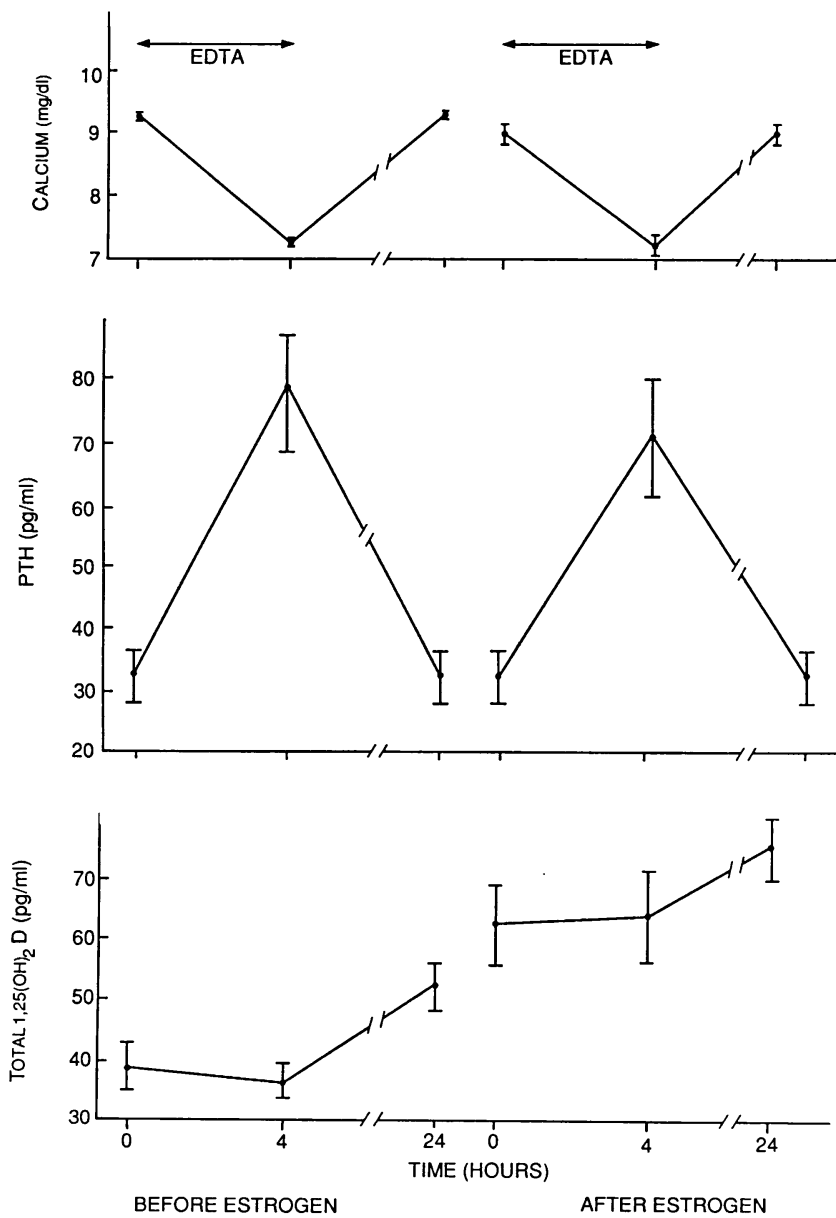

Figure 2. Effect of estrogen on the response to EDTA infusion in 12 postmenopausal women. (Top) Serum calcium; (middle) iPTH; (bottom) total calcitriol. Arrows at top, duration of EDTA infusion. 
oral contraceptives. It is difficult to compare absolute values for free calcitriol by the ultrafiltration technique to the index estimated from the molar calcitriol/DBP ratio. However, the change with estrogen in these two measures was highly correlated, and we conclude that estrogen treatment increases free calcitriol levels in postmenopausal women.

The basis for this rise is not clear. Although estrogen may increase the calcitriol production rate, the contribution of altered sterol clearance to the change in calcitriol level requires evaluation. Even if calcitriol production rate were increased, the proximate stimulus of the rate-limiting renal $1 \alpha$-hydroxylase remains to be identified. Primary regulators of this enzyme include PTH, calcium, and inorganic phosphorus (14-16). Basal iPTH levels did not change on estrogen. Fasting serum calcium concentrations decreased, but the reduction did not correlate significantly with changes in total or free calcitriol, or in the calcitriol/DBP ratio.

A relationship of altered phosphorus metabolism to increased calcitriol production is an attractive possibility. We (Marcus et al., unpublished observations) have previously observed that administration of conjugated estrogens to elderly women under the identical conditions used in this study significantly decreases the efficiency of renal phosphorus reabsorption (TmP/GFR), and Lyles et al. (17) recently demonstrated a significant relationship between TmP/GFR and calcitriol level. Moreover, Maierhofer et al. (18) and Portale et al. (19) have both shown that phosphorus deprivation increases calcitriol levels in healthy men. In this study, serum phosphorus levels decreased significantly after estrogen. However, there was no correlation between the reduction in serum phosphorus and the rise in calcitriol, so this issue remains unresolved. It is possible that the relationship between phosphorus and calcitriol production is more complex than can be determined from single fasting specimens, and more frequent sampling would be necessary for significant correlations to emerge.

Finally, one must consider the possibility that estrogen directly stimulates calcitriol production by modulating $1 \alpha$-hydroxylase activity. Evidence for and against such a direct effect in avian species has been presented (20-23), but there is presently no compelling evidence for a direct effect of estrogen on the hydroxylase system in mammals.

Circulating levels of calcitriol decrease with age in normal humans $(24,25)$. In elderly women, the rise in calcitriol concentration that follows administration of PTH is blunted (26, 27), suggesting that impaired activation of the rate limiting enzyme in calcitriol synthesis, $1 \alpha$-hydroxylase, contributes to the decreased plasma sterol levels. A possible role for estrogen deprivation in this impairment has not been addressed. Because estrogen replacement increases the plasma calcitriol concentration in postmenopausal women (1), it is possible that hydroxylase unresponsiveness may partly reflect the hormonal milieu rather than age per se. If this were true, the calcitriol response to PTH might improve after estrogen replacement. Within the constraints of the experimental protocol, our results provide no support for this hypothesis. Whereas the hypocalcemic challenge increased total and free calcitriol levels in 10 of 12 women with the initial study, only eight subjects showed a rise in free calcitriol after estrogen. Moreover, the group changes in total and free calcitriol after EDTA were the same after as before estrogen, regardless of whether the data are expressed as absolute or relative changes.

Nonetheless, it would be premature to conclude that estro- gen does not modify the sensitivity of $1 \alpha$-hydroxylase to its primary regulators. The stimulus to calcitriol formation in this study was not PTH alone, but the combination of PTH and hypocalcemia. The level of hypocalcemia achieved during the two EDTA studies was the same. However, because basal calcium levels were slightly lower on estrogen, the decrease from basal calcemia was not as great. The induced rise in iPTH was also slightly less during the second study. Thus, neither stimulus was strictly comparable during the two tests. Furthermore, even if the tests had been identical in every detail, one could not draw firm conclusions about enzyme sensitivity from what is essentially a single-point dose response. Comprehensive assessment of renal sensitivity to PTH will require the elaboration of complete response curves to graded doses of hormone.

From the perspective of maintaining bone mass, it is widely accepted that the best opportunity for estrogen replacement therapy is within a few years of menopause, during the period of accelerated bone loss. However, age-related bone loss continues into later decades, and is thought to be sustained by a complex interaction of marginal vitamin D sufficiency, intestinal calcium malabsorption, and compensatory hypersecretion of PTH $(1,9,10,28)$. An estrogen-related increase in biologically effective, free calcitriol levels in women who were on average $>15 \mathrm{yr}$ beyond menopause supports the idea that some of the factors that underlie age-related bone loss may improve with the judicious replacement of estrogen, even in later years.

\section{Acknowledgments}

The authors are pleased to thank Dr. Roger Bouillon for graciously providing measurements of vitamin D binding protein, Dr. Daniel Bikle for his assistance in establishing the centrifugal ultracentrifugation technique, and Dr. David Feldman for thoughtful conversations about this project. Particular thanks are given to Ms. Marilyn Kazemi and the staff of the Aging Study Unit for their enthusiastic and tireless efforts. PTH measurements were expertly carried out by G. Young and M. Cheema.

This study was supported by National Institutes of Health (NIH) grant AGO4458-03A3 (Teaching Nursing Home), and by the Research Service of the Veterans Administration. Dr. Cheema was recipient of NIH Training grant DK-07217.

\section{References}

1. Gallagher, J. C., B. L. Riggs, and H. F. DeLuca. 1980. Effect of estrogen on calcium absorption and serum vitamin D metabolites in postmenopausal osteoporosis. J. Clin. Endocrinol. \& Metab. 51:13591364.

2. Bikle, D. D., E. Gee, B. Halloran, and J. G. Haddad. 1984. Free 1,25-dihydroxy-vitamin $D$ levels in serum from normal subjects, pregnant subjects, and subjects with liver disease. J. Clin. Invest. 74:19661971.

3. Kumar, R., W. R. Cohen, P. Silva, and F. H. Epstein. 1979. Elevated 1,25-dihydroxyvitamin D plasma levels in normal human pregnancy and lactation. J. Clin. Invest. 63:342-344.

4. Bouillon, R., F. A. Van Assche, H. Van Baelen, W. Heyns, and P. De Moor. 1981. Influence of the Vitamin D-binding protein on the serum concentration of 1,25-Dihydroxyvitamin $D_{3}$. Significance of the free 1,25-dihydroxyvitamin D 3 concentration. J. Clin. Invest. 67:589-596.

5. Buchanan, J. R., R. Santen, S. Cauffman, A. Cavaliere, R. B. Greer, and L. M. Demers. 1986. The effect of endogenous estrogen fluctuation on metabolism of 25 -hydroxyvitamin D. Calcif. Tissue Int. 39:139-144. 
6. Haddad, J. G., and J. Walgate. 1976. Radioimmunoassay of the binding protein for vitamin $\mathrm{D}$ and its metabolite in human serum: concentrations in normal subjects and in patients with disorders of mineral metabolism. J. Clin. Invest. 58:1217-1222.

7. Bouillon, R., H. van Baelen, and P. De Moor. 1977. 25-Hydroxyvitamin $\mathrm{D}$ and its binding protein in maternal and cord serum. $J$. Clin. Endocrinol. \& Metab. 45:679-684.

8. Crilly, R. G., D. H. Marshall, A. Horsman, B. E. C. Nordin, and R. Bouillon. 1980. $1 \alpha$-Hydroxy $\mathrm{D}_{3}$ with and without oestrogen in the treatment of osteoporosis. Proceedings of the Osteoporosis Meeting. Madison, WI. (Abstr.)

9. Marcus, R., P. Madvig, and G. Young. 1984. Age-related changes in parathyroid hormone and parathyroid hormone action in normal humans. J. Clin. Endocrinol. \& Metab. 58:223-230.

10. Young, G., R. Marcus, J. R. Minkoff, L. Y. Kim, and G. V. Segre. 1987. Age related increase in parathyroid hormone in man: the use of intact and midmolecule antisera to distinguish hormone secretion from retention. J. Bone Min. Res. 2:367-374

11. Reinhardt, T. A., R. L. Horst, J. W. Orf, and B. W. Hollis. 1984. A microassay for 1,25-dihydroxyvitamin $D$ not requiring high performance liquid chromatography: application to clinical studies. J. Clin. Endocrinol. Metab. 58:91-98.

12. Hammond, G. L., J. A. Nisker, L. A. Jones, and P. K. Siiteri 1980. Estimation of the percentage of free steroid in undiluted serum by centrifugal ultrafiltration-dialysis. J. Biol. Chem. 255:5023-5026.

13. Bouillon, R., H. Van Baelen, and P. De Moor. 1977. The measurement of the vitamin D-binding protein in human serum. $J$. Clin. Endocrinol. Metab. 45:225-231.

14. Henry, H. L., R. J. Midgett, and A. W. Norman. 1974. Regulation of 25-hydroxyvitamin $\mathrm{D}_{3}-1$ hydroxylase in vivo. J. Biol. Chem. 249:7584-7592.

15. Bikle, D. D., and H. Rasmussen. 1975. The ionic control of 1,25-dihydroxy-vitamin $\mathrm{D}_{3}$ production in isolated chick renal tubules. J. Clin. Invest. 55:292-298.

16. Trechsel, U., J. A. Eisman, J. A. Fischer, J.-P. Bonjour, and H. Fleisch. 1980. Calcium-dependent, parathyroid hormone-independent regulation of 1,25-dihydroxyvitamin D. Am. J. Physiol. 239:E119E124.

17. Lyles, K. W., D. L. Halsey, N. E. Friedman, and B. Lobaugh. 1988. Correlations of serum concentrations of 1,25-Dihydroxyvitamin
D, phosphorus, and parathyroid hormone in tumoral calcinosis. $J$. Clin. Endocrinol. \& Metab. 67:88-92.

18. Maierhofer, W. J., R. W. Gray, and J. Lemann, Jr. 1984. Phosphate deprivation increases serum $1,25-(\mathrm{OH})_{2}$-vitamin $\mathrm{D}$ concentrations in healthy men. Kidney Int. 25:571-575.

19. Portale, A. A., B. P. Halloran, M. M. Murphy, and R. C. Morris, Jr. 1986. Oral intake of phosphorus can determine the serum concentrations of 1,25-dihydroxyvitamin $\mathrm{D}$ by determining its production rate in humans. J. Clin. Invest. 77:7-12.

20. Tanaka, Y., L. Castillo, and H. F. DeLuca. 1976. Control of renal vitamin D hydroxylases in birds by sex hormones. Proc. Natl. Acad. Sci. USA. 73:2701-2705.

21. Baksi, S. N., and A. D. Kenny. 1977. Vitamin $D_{3}$ metabolism in immature Japanese quail: effects of ovarian hormones. Endocrinology. 101:1216-1220.

22. Pike, J. W., E. Spanos, K. W. Colston, I. MacIntyre, and M. R. Haussler. 1978. Influence of estrogen on renal vitamin $D$ hydroxylases and serum $1 \alpha, 25-(\mathrm{OH})_{2} \mathrm{D}_{3}$ in chicks. Am. J. Physiol. 235:E338-E343.

23. Henry, H. L. 1981. $25(\mathrm{OH}) \mathrm{D}_{3}$ metabolism in kidney cell cultures: lack of a direct effect of estradiol. Am. J. Physiol. 240:E119E124.

24. Gallagher, J. C., B. L. Riggs, J. Eisman, A. Hamstra, S. B. Arnaud, and H. F. DeLuca. 1979. Intestinal calcium absorption and serum vitamin D metabolites in normal subjects and osteoporotic patients. J. Clin. Invest. 64:729-736.

25. Manolagas, S. C., F. L. Culler, J. E. Howard, A. S. Brickman, and L. J. Deftos. 1983. The cytoreceptor assay for 1,25-dihydroxyvitamin D and its application to clinical studies. J. Clin. Endocrinol. \& Metab. 56:751-760.

26. Slovik, D. M., J. S. Adams, R. M. Neer, M. F. Holick, and J. T. Potts, Jr. 1981. Deficient production of 1,25-dihydroxyvitamin D in elderly osteoporotic patients. N. Engl. J. Med. 305:372-374.

27. Tsai, K.-S., H. Heath III, R. Kumar, and B. L. Riggs. 1984. Impaired vitamin $\mathrm{D}$ metabolism with aging in women. Possible role in pathogenesis of senile osteoporosis. J. Clin. Invest. 73:1668-1672.

28. Forera, M. S., R. F. Klein, R. A. Nissenson, K. Nelson, H. Heath III, C. D. Arnaud, and B. L. Riggs. 1987. Effect of age on circulating immunoreactive and bioactive parathyroid hormone levels in women. J. Bone Min. Res. 2:363-366. 